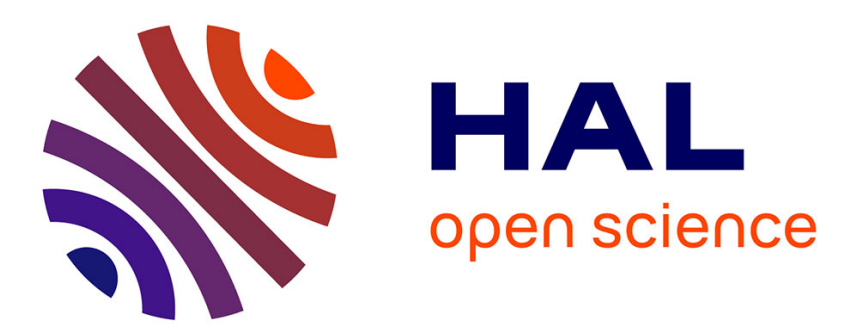

\title{
Improved robustness of AlGaN/GaN HEMTs using Deuterium to passivate the structural defects
}

Jean-Guy Tartarin, Guilhem Astre, Laurent Bary, Jacques Chevallier, S Delage $^{\circ}$

\section{- To cite this version:}

Jean-Guy Tartarin, Guilhem Astre, Laurent Bary, Jacques Chevallier, S Delage ${ }^{\circ}$. Improved robustness of AlGaN/GaN HEMTs using Deuterium to passivate the structural defects. Conference on Optoelectronic and Microelectronic Materials and Devices (COMMAD 2008), Jul 2008, Sydney, Australia. 10.1109/COMMAD.2008.4802078 . hal-01343322

\section{HAL Id: hal-01343322 \\ https://hal.science/hal-01343322}

Submitted on 22 May 2018

HAL is a multi-disciplinary open access archive for the deposit and dissemination of scientific research documents, whether they are published or not. The documents may come from teaching and research institutions in France or abroad, or from public or private research centers.
L'archive ouverte pluridisciplinaire HAL, est destinée au dépôt et à la diffusion de documents scientifiques de niveau recherche, publiés ou non, émanant des établissements d'enseignement et de recherche français ou étrangers, des laboratoires publics ou privés. 


\title{
Improved Robustness of AlGaN/GaN HEMTs using Deuterium to Passivate the Structural Defects
}

\author{
J.G. Tartarin", G. Astre", L. Bary\#, J. Chevallier ${ }^{+}$, S. Delage ${ }^{\circ}$. \\ ${ }^{*}$ University of Toulouse, LAAS CNRS \& Paul Sabatier University, 7 av. Colonel Roche, 31.077 Toulouse cedex 4, France \\ ${ }^{+}$GEMaC, 1 place Aristide Briand, 92195 Meudon, France \\ TIGER, Alcatel-Thales III-V Lab, Route de Nozay, 91460 Marcoussis, France \\ Email: tartarin@laas.fr \\ Telephone: +33(0) 561.337.996, Fax: +33(0) 561.336.969
}

\begin{abstract}
GaN related devices have demonstrated excellent performances for high power, high temperature up to $\mathrm{X}$-band applications. However, even if the reliability studies on AlGaN/GaN high electron mobility transistors (HEMT) have led to higher mean time to failure (MTTF), physical mechanisms induced by stresses are still not well known. This paper proposes an original solution to improve the robustness of the devices by passivating the traps that are supposed to be related to the degradation process. Based on the experience of previous works, we use Deuterium $\mathrm{H}+$ to block the traps located at the AlGaN/GaN interface above the gated zone of the device, and the traps in the bulk of the conducting channel ( 2 dimensions electron gas : 2DEG). 2 batches of devices are processed with and without deuterium, and submitted to temperature stresses at $500^{\circ} \mathrm{C}$. Low frequency noise (LFN) measurements are performed to track the evolution of the spectral current density of the drain current, which is known to be related to the structural evolution of the traps and of the crystal structure perfection. Devices with deuterium feature stable LFN spectra, while LFN spectra of the devices without deuterium evolve during the different stress steps. Thus, deuterium can offer an interesting alternative to enhance the robustness of $\mathrm{AlGaN} / \mathrm{GaN}$ devices operating under stringent temperature conditions.
\end{abstract}

Keywords-component; AlGaN/GaN HEMT, Low Frequency Noise, deuterium, trapping detrapping centers, 1/f flicker noise, robustness.

\section{INTRODUCTION}

Wide bandgap technologies are already available for photonic applications. They also target power switches, rectifiers (automotive and embedded systems applications) and robust high frequency systems (like power amplifiers, low noise amplifiers, oscillators in radar and telecommunication transceivers). These electronic systems operate at very high temperatures with high power management, where silicon devices must operate at junction temperature below approximately $200^{\circ} \mathrm{C}$, at lower power levels and lower operating frequencies: the $\mathrm{GaN}$ electronic market directly depends on the opportunity to design devices able to operate securely at high temperature levels. Reliability studies are at their very early stage for GaN based devices such as
AlGaN/GaN high electron mobility transistors (HEMT). However, commercial factories have announced a 1 million hour operating time for devices biased at a drain-source voltage of $28 \mathrm{~V}$ [1]. This study is based on previous works performed on devices grown on sapphire, silicon $(\mathrm{Si})$ and silicon carbide (SiC) devices: low frequency noise (LFN) and secondary ion mass spectroscopy (SIMS) measurements have been used to locate the main structural defects of the transistors under its gated zone, at the $\mathrm{AlGaN} / \mathrm{GaN}$ interface and in the two dimension electron gas (2DEG) channel [2][3]. From LFN measurements, we have evidence for trapping-detrapping centres with activation energies at $0.21 \mathrm{eV}$ and $0.38 \mathrm{eV}$ attributed to $\mathrm{V}_{\mathrm{N}}$ vacancy and to a donor centre $\mathrm{Mg}_{\mathrm{Ga}}-\mathrm{V}_{\mathrm{N}}$ in the 2DEG [4]. SIMS measurements have revealed high defect concentrations in the above GaN layer and at the AlGaN/GaN interface (with concentrations levels higher than $10^{20} \mathrm{~cm}^{-3}$ )(fig. 1). From this earlier experiment using deuterium as a probe to mark the defects in the transistor's layers, we propose here to take advantage of the deuterium in diffusion conditions through the AlGaN layer to inhibit the traps and defects that are supposed to be the precursors of failure modes of the devices.

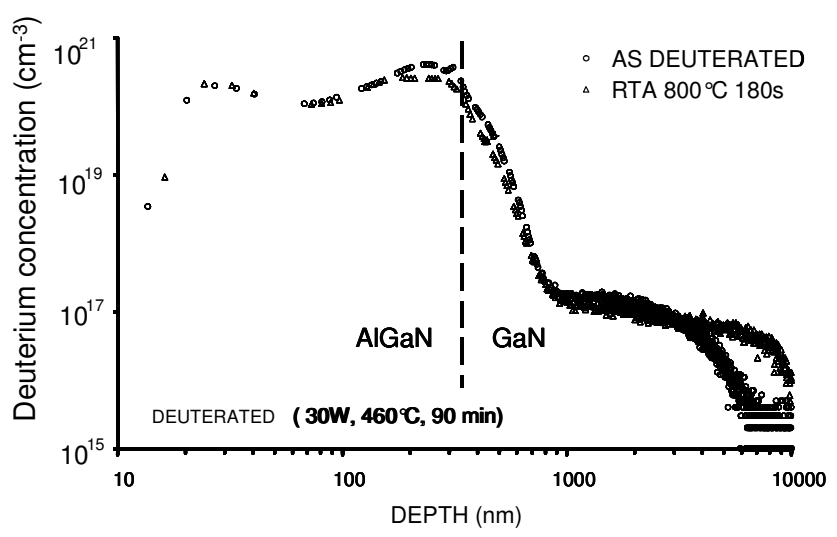

Figure 1. SIMS profile of Deuterium distribution from AlGaN to GaN layers

Moreover, the diffusion of deuterium must not alter the electrical properties of the devices (mobility, carrier density in 
the channel). The first section of the paper presents the main technological features of the devices under test (one batch of devices with deuterium and one batch of devices without deuterium), associated to electrical scattering of the two batches under test. In the second section, the stress plan is exposed with the associated results on LFN and electrical measurements. The last paragraph exposes some early tracks to understand the invoked mechanisms, and the results of this experiment are given in the conclusions.

\section{ALGAN/GAN HEMT ON SILICON SUBSTRATE}

The HEMT devices featuring $0.25 \times 2 \times 75 \mu \mathrm{m}^{2}$ gate area are grown on silicon substrate using metal organic chemical vapor deposition (MOCVD) process [5]. The AlGaN alloy uses 24\% content of aluminum. Electrical measurements, including scattering-parameters, static and pulsed measurements have been performed using a batch of samples for each different gate geometry (length, width) proving the good yielding of the wafer over more than 50 devices. These devices from the same wafer are divided into two batches of deuterated and nondeuterated transistors, and 3 test samples. The deuteration process consists in the deposition of a tank of deuterium between source and drain before the metallization of the gate. Then, an RF plasma under elevated temperature (3W during $180 \mathrm{~s}$ at $300^{\circ} \mathrm{C}$ ) is used to diffuse the deuterium through the AlGaN layer down to the $\mathrm{AlGaN} / \mathrm{GaN}$ interface and in the 2DEG as shown in fig.2 (cf. fig.1 for the concentration distribution through the $\mathrm{AlGaN}$ and $\mathrm{GaN}$ layers). Thus, $\mathrm{H}^{+}$ bonds to the defects for the deuterated devices. Moreover, these conditions of deuteration maintain the mobility $\mu$ and the number of carriers $n_{i}$ at the same values than for the devices without deuterium. A rapid thermal annealing (RTA) can also be used to recover $\mu$ and $n_{i}$ when needed. The drain saturation current $I_{D S S}=670 \mathrm{~mA} / \mathrm{mm}$, the resistance $R_{O N}=44 \Omega$ (measured at $\mathrm{V}_{\mathrm{GS}}=0 \mathrm{~V}$ ), the gate leakage currents $\mathrm{I}_{\mathrm{G}}<0.1 \mu \mathrm{A}$ and the transconductance gain $\mathrm{g}_{\mathrm{m}}$ evidence a good technological mastering with less than $5 \%$ deviation from the nominal values (except for $\mathrm{I}_{\mathrm{G}}$ with a maximum value at $0.1 \mu \mathrm{A}$ ).

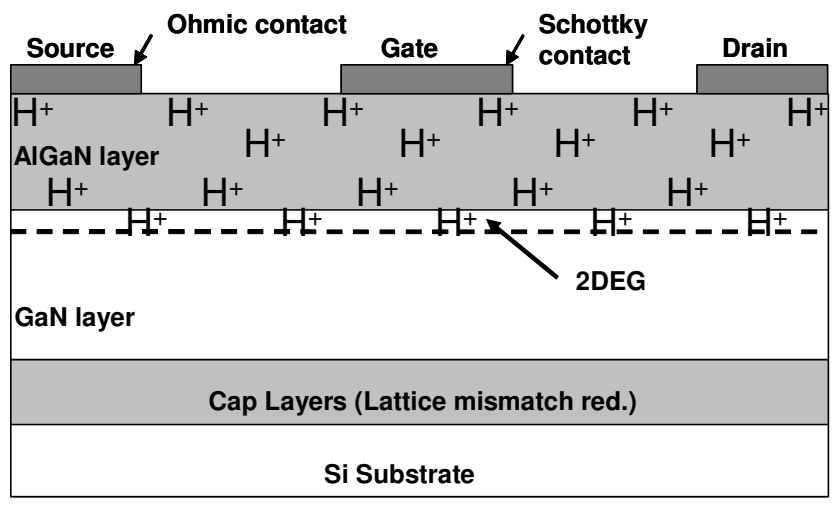

Figure 2. Diffusion of $\mathrm{H}^{+}$from $\mathrm{AlGaN}$ downto $\mathrm{GaN}$ layer to passivate the defects under the gated zone of the device at the AlGaN/GaN interface and in the $2 \mathrm{DEG}$ channel. A $3 \mathrm{~W}$ RF plasma is applied during 180 s at $300^{\circ} \mathrm{C}$.

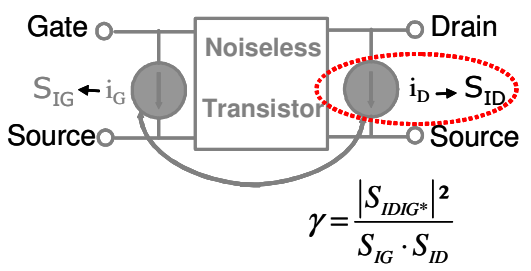

Figure 3. Electrical representation of a noisy HEMT, with two correlated low frequency current noise sources at the gate and drain accesses (resp. $\mathrm{S}_{\mathrm{IG}}$ and $\left.\mathrm{S}_{\mathrm{ID}}\right) \cdot \gamma$ represents the coherence of these correlated noise sources.

LFN measurements are performed using a transimpedance amplifier direct measurement technique [6] which allows rapid LFN measurements over a wide frequency range (from $10 \mathrm{~Hz}$ to $100 \mathrm{kHz}$ for this study). LFN measurements provide valuable information about noise source location, but can also be used to track the defects versus stress conditions to assess the devices robustness. The noisy transistor can be modeled with two correlated current noise sources at the input and at the output of the device, as proposed in fig. 3. The correlation coefficient $\gamma$ if found to be null $\left(<10^{-3}\right)$, and only the drain current noise spectral density $\mathrm{S}_{\mathrm{ID}}$ (or its normalized representation, dividing by the drain current $\mathrm{S}_{\mathrm{ID}} / \mathrm{I}_{\mathrm{D}}$ ) is presented in the next sections for interpretation. A good homogeneity is measured over the 50 devices before the application of the stress (fig. 4). The LFN spectra are constituted by $1 / \mathrm{f}^{\gamma}$ flicker noise sources, and the noise spectral density of the deuterated and non-deuterated devices are in the same order of magnitude.
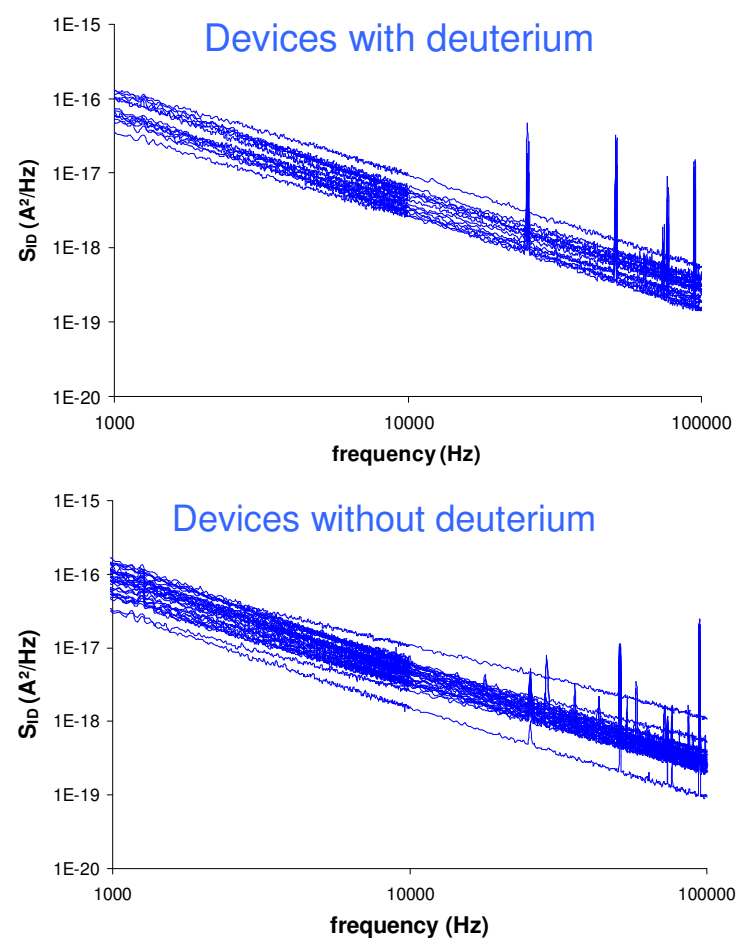

Figure 4. Low frequency noise spectral density of the drain current noise source $S_{\text {ID }}$ of 16 deuterated devices and 32 devices without deuterium, before stress (bias conditions, $\mathrm{V}_{\mathrm{GS}}=-3 \mathrm{~V}, \mathrm{~V}_{\mathrm{DS}}=10 \mathrm{~V}$ ). 
Each batch of devices (with and without deuterium) is composed of 8 representative transistors (i.e. with identical electrical and noise characteristics). A test sample is measured at each stress step to assess the workbenches reproducibility.

\section{STRESS RESULTS}

Temperature is used as an accelerating stress factor to study the effect of the passivation of the traps by deuterium on the devices. The stress plan is given in fig. 5: different temperature stresses at $500^{\circ} \mathrm{C}$ are applied to the two batches of transistors (@ $\mathrm{T}_{0}, \mathrm{~T}_{1}, \mathrm{~T}_{4}, \mathrm{~T}_{6}$ and $\mathrm{T}_{7}$ ), with a 10 months interruption period in storage condition at ambient temperature $\left(\mathrm{T}_{2}\right)$. Some stresses at $200^{\circ} \mathrm{C}$ during 15 minutes are used to check the sensitivity of the LFN devices with different temperature levels $\left(T_{3}\right.$ and $\left.T_{5}\right)$. The goal of this study is not to give any accelerating factor of degradation with temperature, but to assess the deuterium impact on devices subjected to high temperature levels. The test sample LFN measurements are stable during the measurement campaign from $\mathrm{T}_{0}$ to $\mathrm{T}_{8}$.

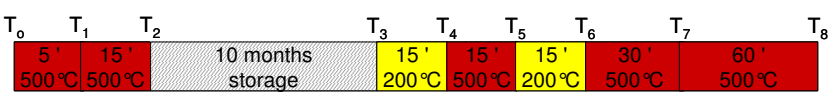

Figure 5. Stress plan composed of temperature stress steps $(5 \mathrm{~min}$. to 60 min. @ $500^{\circ} \mathrm{C}$ and $15 \mathrm{~min}$. @ $200^{\circ} \mathrm{C}$ ), and 10 months of storage (ambient conditions).

Plots of figure 6 to figure 8 uses $S_{I D} / I_{D}$ that represents the drain current noise spectral density (current low frequency noise or fluctuations, noticed LFN) divided by the drain current $I_{D}$. The LFN spectra evolve differently for the two batches of devices:

-LFN of devices with deuterium remains stable, or sometimes improves with temperature stress steps (fig.6 for $\mathrm{T}_{0}, \mathrm{~T}_{2}$ and $\mathrm{T}_{8}$ ). Improvement can be attributed to a redistribution of $\mathrm{H}^{+}$under high temperature conditions. All the static and dynamic characteristics remain stable for devices with deuterium.

-However, devices without deuterium are sensitive to the different temperature stresses: the LFN spectra of the devices from this sample evolve largely with temperature, but these evolutions of the spectra are not monotonous (as for the device in fig.7@ $\mathrm{T}_{0}, \mathrm{~T}_{2}$ and $\mathrm{T}_{8}$ for example). Some temperature stresses degrade, or sometimes improve the LFN spectra. So the origin of this degradation is not associated to a unique event, and different mechanisms can be invoked, associated to different noise sources $\left(1 / \mathrm{f}^{\gamma}\right.$ flicker noise source or trappingdetrapping Lorentzian noise source). The noise behavior of the devices without deuterium can be related to structural defects (dislocations, traps,...) or electrical instabilities (surface or bulk charges that induce gate leakage currents) that can be correlated or not. Additional reliability tests are performed to identify these mechanisms, which are not in the scope of this article.

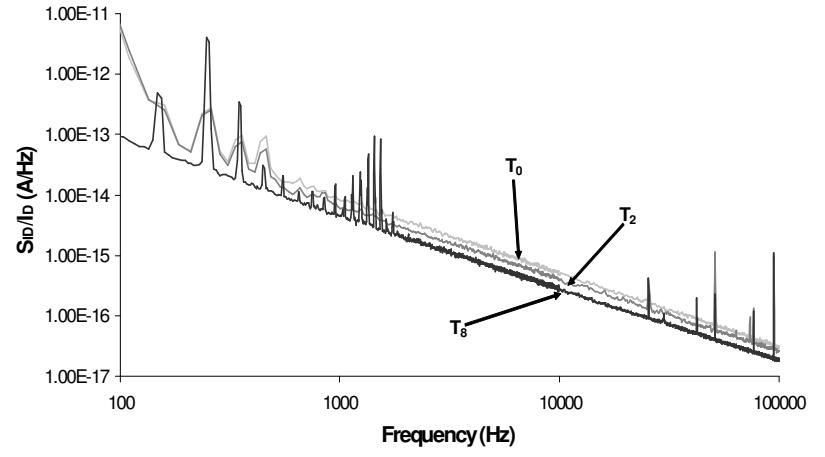

Figure 6. LFN spectra of the normalized drain current noise spectral density $\mathrm{S}_{\mathrm{ID}} / \mathrm{I}_{\mathrm{D}}$ of a device from the deuterated batch, measured at $\mathrm{T}_{0}, \mathrm{~T}_{2}$ and $\mathrm{T}_{8}$ (bias conditions, $\mathrm{V}_{\mathrm{GS}}=-3 \mathrm{~V}, \mathrm{~V}_{\mathrm{DS}}=10 \mathrm{~V}$ ).

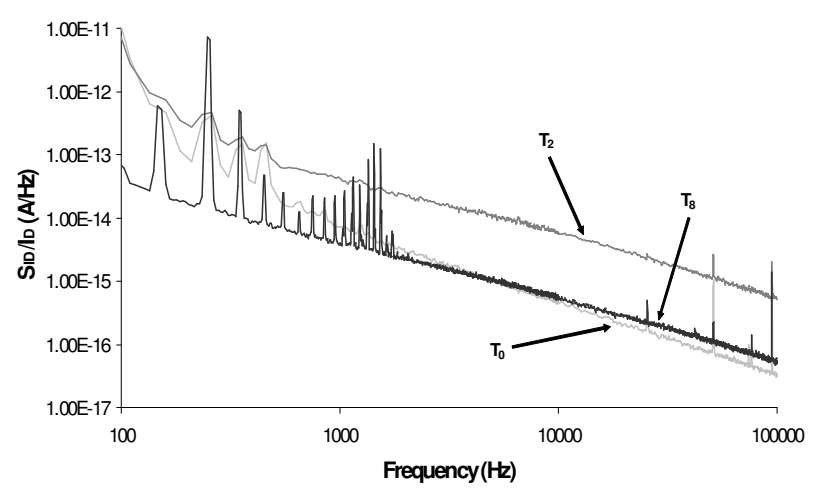

Figure 7. LFN spectra of the normalized drain current noise spectral density $\mathrm{S}_{\mathrm{ID}} / \mathrm{I}_{\mathrm{D}}$ of a device from the non-deuterated batch, measured at $\mathrm{T}_{0}$, $\mathrm{T}_{2}$ and $\mathrm{T}_{8}$ (bias conditions, $\mathrm{V}_{\mathrm{GS}}=-3 \mathrm{~V}, \mathrm{~V}_{\mathrm{DS}}=10 \mathrm{~V}$ ).

Figure 8 reports on the evolution of the current noise spectral density $\mathrm{S}_{\mathrm{ID}}$ measured at $10 \mathrm{kHz}$ for the different time steps. Two different effects can be separated: the temperature stress $\left(T_{0}\right.$ to $T_{2}$ and $T_{3}$ to $\left.T_{8}\right)$ and the 10 months storage period $\left(T_{2}\right.$ to $\left.T_{3}\right)$. The storage period affects both batches with an increase of the drain current spectral density $\mathrm{S}_{\mathrm{ID}}$, but this variation of $\mathrm{S}_{\mathrm{ID}}$ can be totally recovered by a $200^{\circ} \mathrm{C}$ thermal annealing. Nevertheless, the test sample's noise characteristics $\mathrm{S}_{\text {ID }}$ remain perfectly stable from $\mathrm{T}_{0}$ to $\mathrm{T}_{8}$ (fig. 8). Thus it can be concluded that the degradation during the 10 months storage period is correlated with the previous thermal stresses $\left(\mathrm{T}_{0}\right.$ to $\mathrm{T}_{2}$ ). The Schottky barrier is sensitive to high temperature stresses, and long term storage might modify the distribution of charges between gate and drain. The next $200^{\circ} \mathrm{C}$ step recovers the former charge distribution (same output I-V characteristics). Thus, only the thermal stress periods $T_{0}$ to $T_{2}$ and $T_{4}$ to $T_{8}$ can single out the effect of the deuterium between the two batches. The bottom part in fig. 8 related to the batch without deuterium features large variations of $\mathrm{S}_{\mathrm{ID}}$, with no monotonous trend (cf. grey area for the maximum variation on the mean value). The top part of fig. 8 
related to the batch with deuterium provides minor variation (if except the storage period $\mathrm{T}_{2}$ to $\mathrm{T}_{4}$ ).
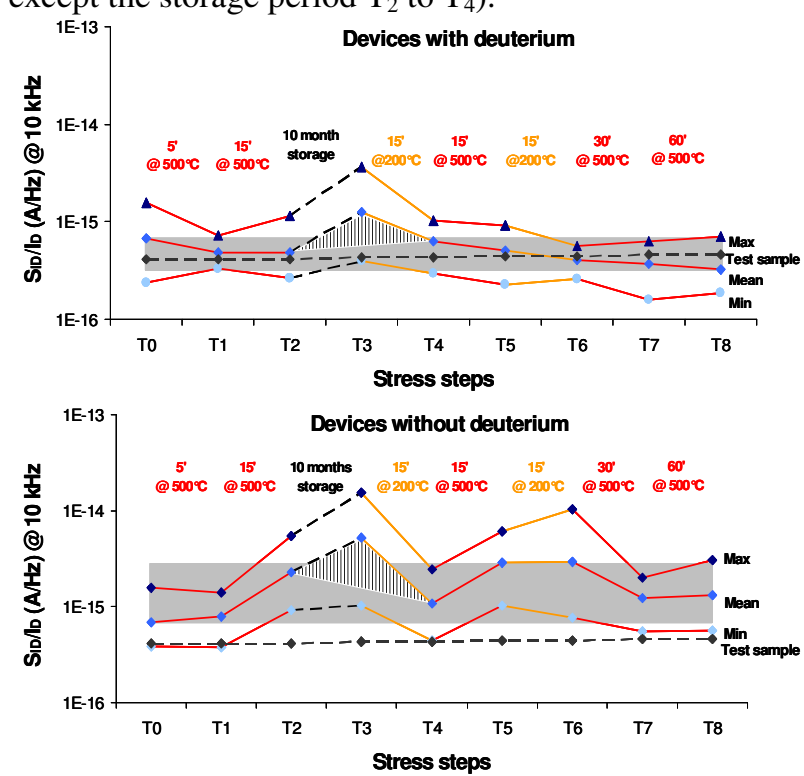

Figure 8. Evolution of the normalized drain current noise spectral density $\mathrm{S}_{\mathrm{ID}} / \mathrm{I}_{\mathrm{D}}(@ 10 \mathrm{kHz})$ versus stress steps $\left(\mathrm{V}_{\mathrm{GS}}=-3 \mathrm{~V}, \mathrm{~V}_{\mathrm{DS}}=10 \mathrm{~V}\right)$.

From these different figures (fig.6 to fig. 8), it is obvious that Deuterium has an impact on the stability of the devices: the traps that are responsible of the degradation of the devices without deuterium are passivated once deuterium is introduced. Hot electron caption by traps (acceptor) can explain the behaviour of the devices without deuterium. Once the traps are passivated, acceptors are passivated by deuterium at $\mathrm{AlGaN} / \mathrm{GaN}$ interface and in the 2DEG channel, thus leading to a more reliable process.
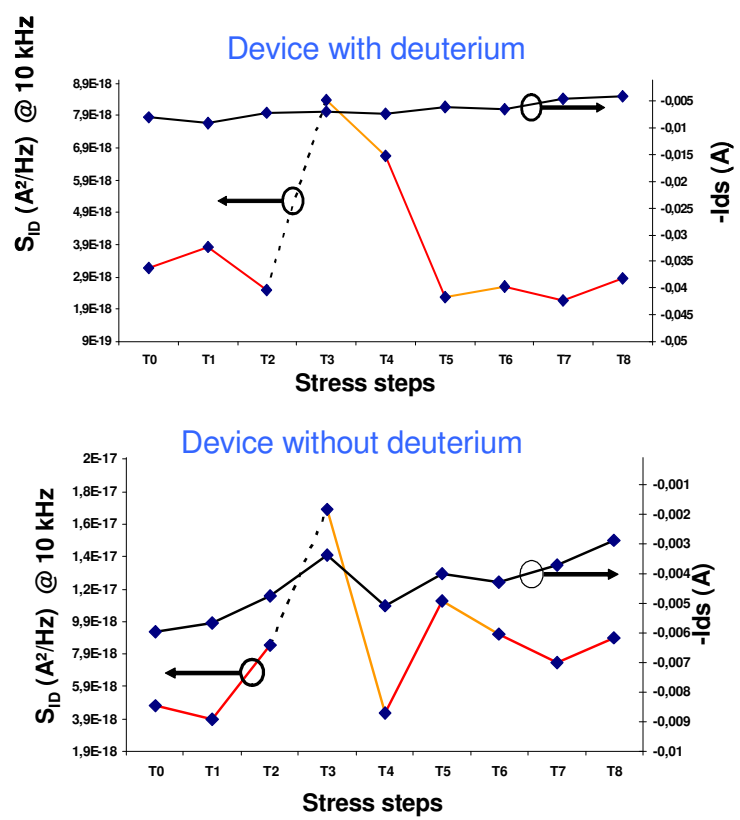

Figure 9. Evolution of the noise spectral current density $\mathrm{S}_{\mathrm{ID}}$ (@ 10kHz) and of the drain current $I_{D}$ using one decade variation scale for both yaxis, versus stress steps (bias conditions, $\mathrm{V}_{\mathrm{GS}}=-3 \mathrm{~V}, \mathrm{~V}_{\mathrm{DS}}=10 \mathrm{~V}$ ).
To corroborate this assumption, fig.9 proposes a comparison between $S_{I D}$ and $I_{D}$ for two typical devices from each batch: all devices from the same batch have the same behaviour. The scale for $I_{D}$ and the scale for $S_{I D}$ feature a one decade variation in figure 9 to easier the comparisons of the trends between $I_{D}$ and $S_{I D}$. While the drain current $I_{D}$ of the device with deuterium remains perfectly stable, $S_{\text {ID }}$ degrades largely only during the storage period. For the device without deuterium, the drain current $\mathrm{I}_{\mathrm{D}}$ evolves in a relative good accordance with $S_{I D}$ (even during the storage period). The absence of deuterium affects not only the structure of the device $\left(\mathrm{S}_{\mathrm{ID}}\right)$ but also its electrical characteristics $\left(\mathrm{I}_{\mathrm{D}}\right)$ for a given biasing condition.

\section{CONCLUSIONS}

Temperature stresses are one of the more stringent conditions for electrical devices dedicated to high power, high temperature management. The use of deuterium can be an efficient solution to improve the reliability of $\mathrm{GaN}$ devices. HEMT devices issued from the same wafer are processed with deuterium for a half wafer, and without deuterium on the second half of the wafer. The diffusion of deuterium down to the defects of the devices at the $\mathrm{AlGaN} / \mathrm{GaN}$ interface and in the 2DEG channel passivates the acceptors and makes the process more reliable versus temperature. Devices without deuterium have their electrical and noise characteristics evolving during the different stress steps. Moreover, the diffusion of deuterium in the devices' layers, using specific conditions does not modify the electrical and noise performances of the transistors.

\section{REFERENCES}

[1] Technology report 'High power developments emphasize semiconductor materials', High Frequency Electronics, August 2007, pp. 30-32.

[2] J.G. Tartarin et al. 'Using low frequency noise characterization of $\mathrm{AlGaN} / \mathrm{GaN}$ HEMT as a tool for technology assessment and failure prediction', Fluctuation And Noise, Las Palmas, Spain, May 2004, Noise in Devices and Circuits II, proceedings of SPIE, Vol. 5470, ISBN 0-8194-5396-X, pp.296-306I.

[3] J.G. Tartarin et al. 'Low frequency noise of AlGaN/GaN HEMT grown on $\mathrm{Al}_{2} \mathrm{O}_{3}$, $\mathrm{Si}$ and $\mathrm{SiC}$ substrates', 18th International Conference on Noise and Fluctuations (ICNF'2005), Salamanque (Espagne), 19-23 Septembre 2005, Noise and Fluctuations, AIP Conference Proceedings 780, American Institute of Physics, 2005, ISBN 0-7354-0267-1, pp.299-302

[4] J.G. Tartarin, G. Soubercaze-Pun, J.L. Grondin, L. Bary, J. MimilaArroyo, J. Chevallier, 'Generation-recombination defects in AlGaN/GaN HEMT on SiC substrate, evidenced by low frequency noise measurements and SIMS characterization', 19th International Conference on Noise and Fluctuations (ICNF2007), Tokyo (Japon), 9-14 Septembre 2007, pp.163-166.

[5] M.A di Forte-Poisson et al., 'MOCVD growth of group III nitrides for high power, high frequency applications' in Phys. Stat. Sol. (c) 2, No. 3, 2005, pp. 947-955.

[6] L. Bary et al. 'Transimpedance amplifier based full low frequency noise characterization set-up for Si/SiGe HBT's' IEEE Transactions on Electron Devices, Vol.48, N4, pp.767-773, Avril 2001. 